\title{
Simulation Analysis of Feisha Reinforced Concrete U-shaped Section Aqueduct
}

\author{
Ji Dongyu \\ Hunan Urban Construction College \\ Xiangtan, China \\ hnjdy@126.com
}

\author{
Yang Zhichao \\ Yellow River Henan Bereau \\ Zhengzhou, China \\ yuluem@sina.com
}

\begin{abstract}
Feisha aqueduct is located at west main canal of irrigation district in the Xinjin county, Liaoning province, the aqueduct is reinforced concrete rib arch aqueduct, arch centering is variable cross-section reinforced concrete double rib structure, arch axis is parabola, clear span is $33 \mathrm{~m}$, rise-span ratio is $1 / 3$. Aqueduct is a important conveyance structure, this paper uses three dimensional finite element method to simulate and analyse Feisha reinforced concrete $U$-shaped section aqueduct, and researchs stress and deformation distribution of aqueduct during construction and operation period. Research results show that Feisha reinforced concrete $U$-shaped section aqueduct structure is reasonable, stressing definite, can satisfy engineering requirement. Feisha aqueduct adopts reinforced concrete rib arch scheme is reasonable. Aqueduct structure is stressing definite, simple, convenient for construction. Vertical displacement of aqueduct structure is small, can meet stiffness requirement.
\end{abstract}

Keywords- Reinforced concrete aqueduct; Finite element method; Simulation analysis; Stress distribution; Calculation model.

\section{INTRODUCTION}

Feisha aqueduct is located at west main canal of irrigation district in the Xinjin county, Liaoning province, design discharge is $6.0 \mathrm{~m}^{3} / \mathrm{s}$, longitudinal slope is $1 / 850$, total length is $840 \mathrm{~m}$. This aqueduct is reinforced concrete rib arch aqueduct[1], arch centering is variable cross-section reinforced concrete double rib structure, arch axis is parabola, clear span is $33 \mathrm{~m}$, rise-span ratio is $1 / 3$. Reinforced concrete single bent and aqueduct bracket on the arch, maximum height of bent on the arch is $8.51 \mathrm{~m}$. Aqueduct body is equal span double cantilever wire mesh concrete U-shaped section aqueduct, length of each span is $8.75 \mathrm{~m}$. Concrete strength grade of aqueduct body is C30, concrete strength grade of bent and arch centering is C20, reinforced strength grade is II[2].

\section{CALCULATION MODEL}

\section{A Model Parameters.}

Concrete strength grade of Feisha aqueduct is $\mathrm{C} 25$, elastic modulus of concrete is $28 \mathrm{GPa}$, poisson's ratio of concrete is $0.167[3-4]$, bulk density is $24 \mathrm{kN} / \mathrm{m}^{3}$. Concrete strength grade of bent and arch is C20, elastic modulus of concrete is $25.5 \mathrm{GPa}$, poisson's ratio of concrete is $0.167[5-6]$, bulk density is $24 \mathrm{kN} / \mathrm{m}^{3}$..

\section{B Model Element.}

Aqueduct structure model adopts SOLID95 element, the element has 20 nodes, each node has three translational degrees of freedom[7]. The element allows irregular shape, and will not reduce calculation accuracy, especially suitable for curve boundary model, at the same time, compatibility of migration shape is good[8-9]. Finite element calculation model of aqueduct structure shows in the Fig.1.

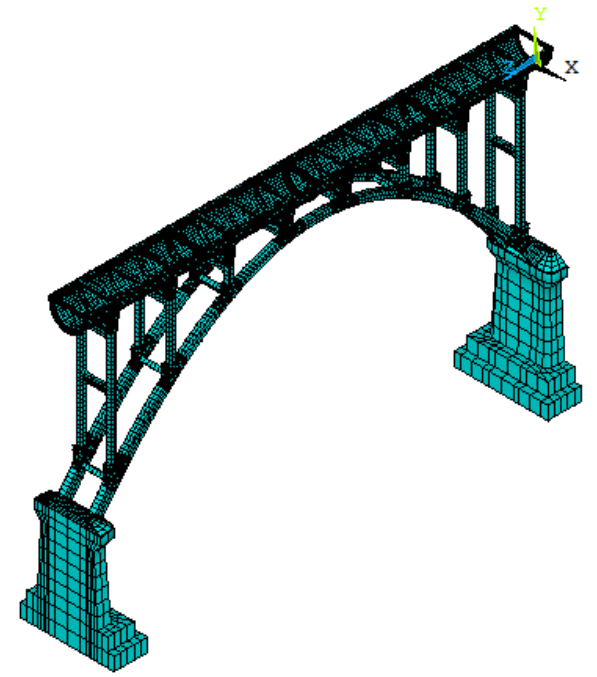

Figure 1. Finite element calculation model of aqueduct structure 


\section{Calculation Cases}

Based on mechanical characteristics of aqueduct structure during construction and operation period[10], mainly consider the following 5 kinds of calculation cases: case 1 , dead weight; case 2 , dead weight and half aqueduct water level; case 3 , dead weight and design water level; case 4, dead weight and full aqueduct water level; case 5, dead weight and design water level and seismic action.

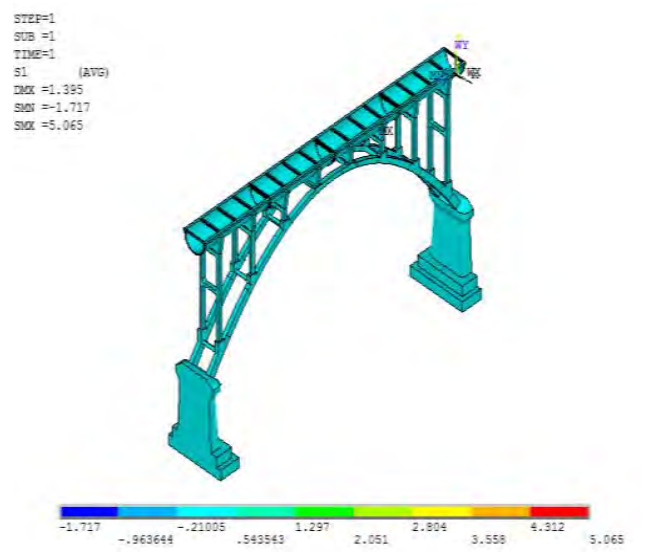

Figure 2. The first principal stress nephogram of aqueduct under case $1(\mathrm{MPa})$

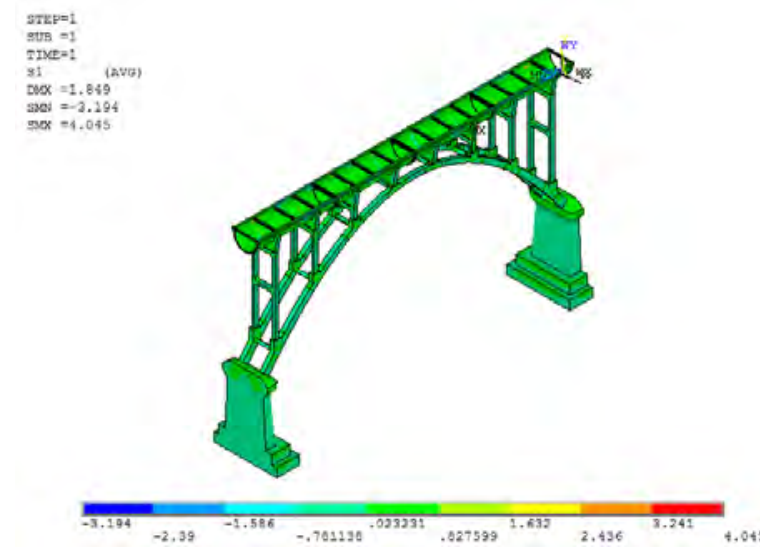

Figure 4. The first principal stress nephogram of aqueduct under case $2(\mathrm{MPa})$

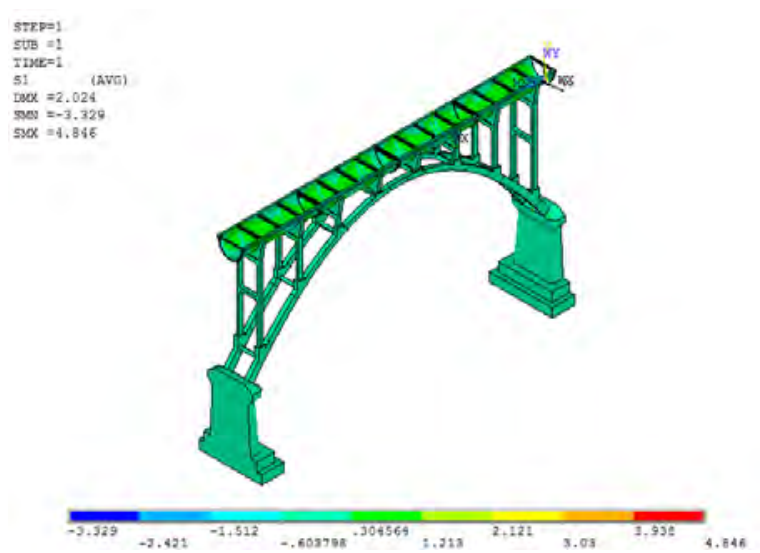

Figure 6. The first principal stress nephogram of aqueduct under case 3 (MPa)

\section{STRUCTURE ANALYSIS OF AQUEDUCT}

A Stress Analysis.

Through three-dimensional finite element simulation analysis of reinforced concrete rib arch aqueduct structure, can get stress nephogram of aqueduct structure during construction and operation period, that shows in Fig .2 to Fig .11.

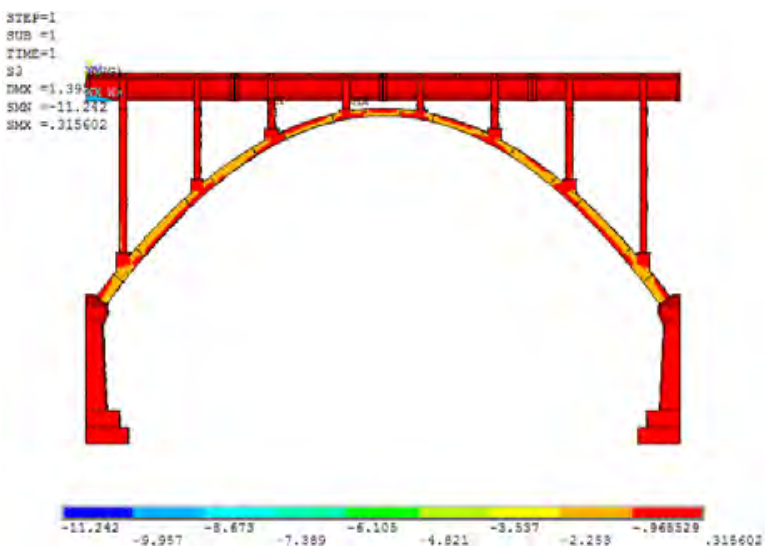

Figure 3. The third principal stress nephogram of aqueduct under case $1(\mathrm{MPa})$

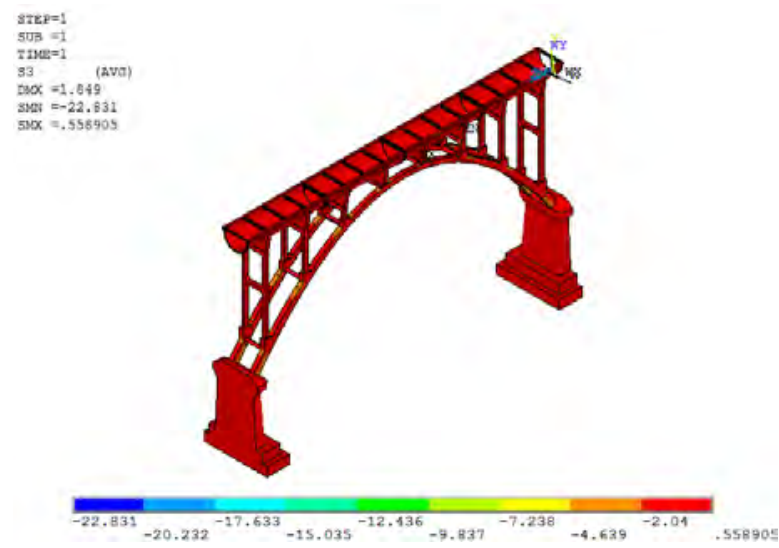

Figure 5. The third principal stress nephogram of aqueduct under case 2 (MPa)

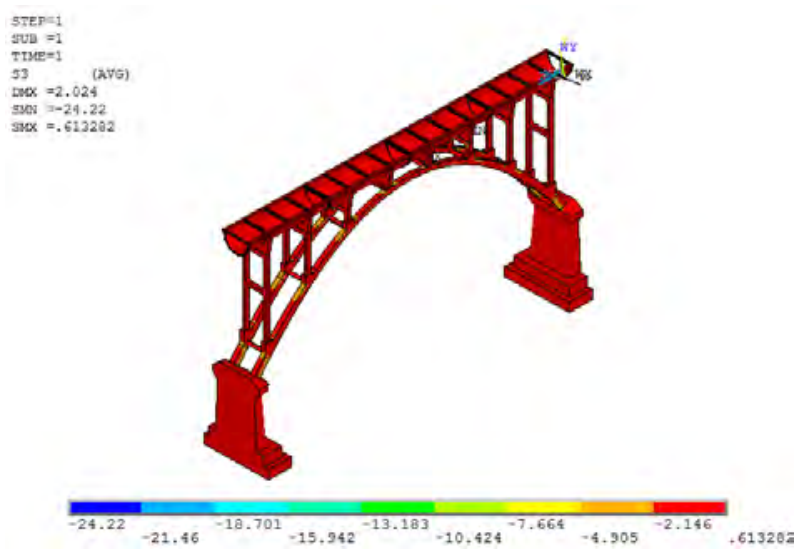

Figure 7. The third principal stress nephogram of aqueduct under case $3(\mathrm{MPa})$ 


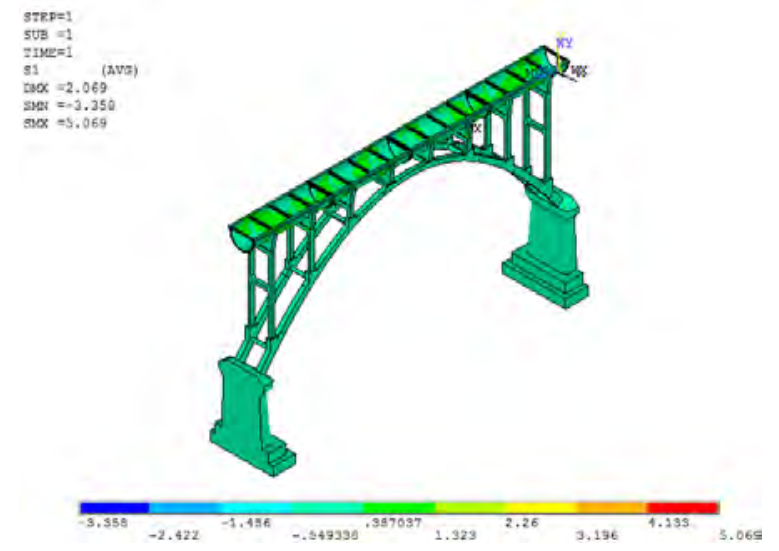

Figure 8 . The first principal stress nephogram of aqueduct under case $4(\mathrm{MPa})$

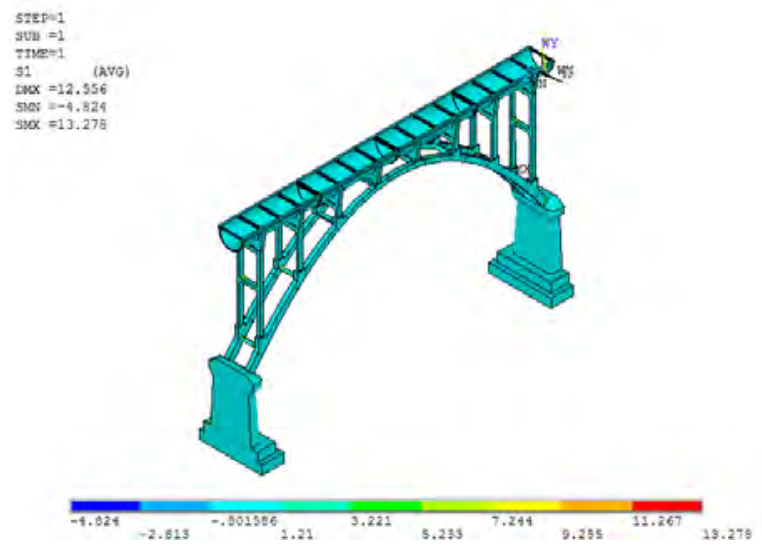

Figure 10. The first principal stress nephogram of aqueduct under case $5(\mathrm{MPa})$

As can be seen from Fig .2 to Fig .11, under different cases, the first principal stress of aqueduct gradually increased with the increase of water pressure, maximum stress value of aqueduct mainly appears in the junction of bent and arch, seismic action has large impact on stress. The maximum first principal stress is $13.28 \mathrm{MPa}$, which appears in the junction of bent and arch under case 5. The maximum third principal stress is -27.57

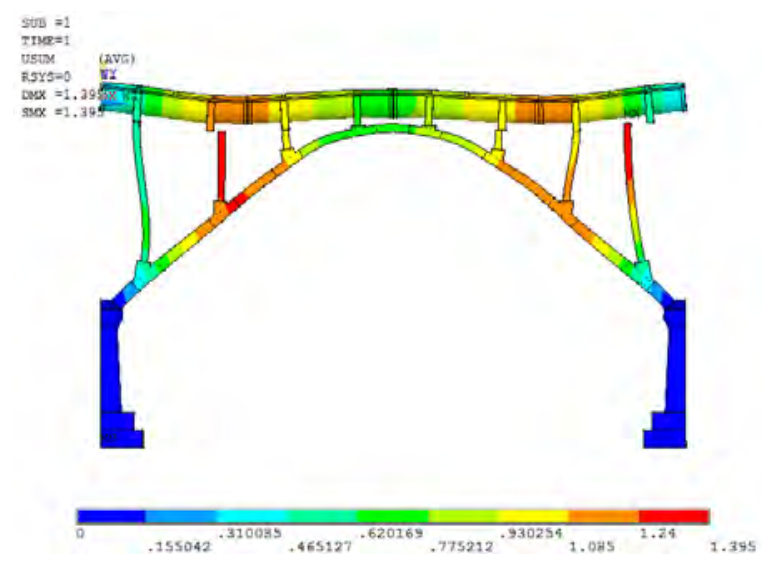

Figure 12. Total displacement nephogram of aqueduct under case 1 (mm)

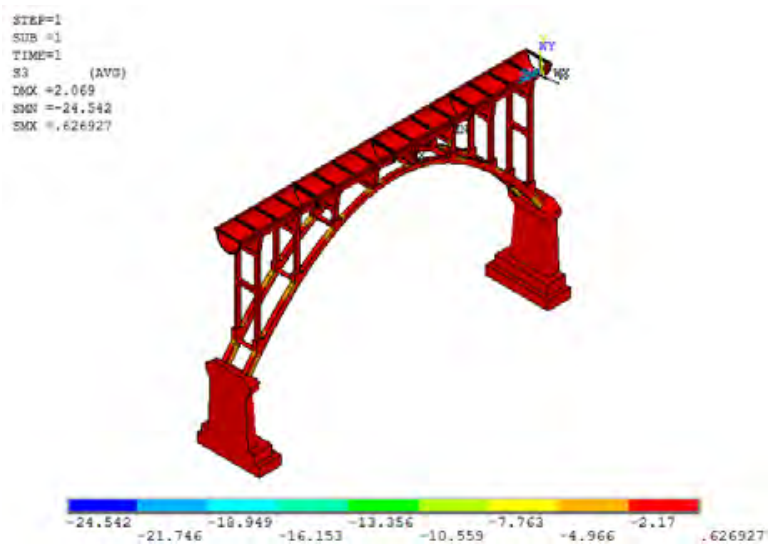

Figure 9. The third principal stress nephogram of aqueduct under case $4(\mathrm{MPa})$

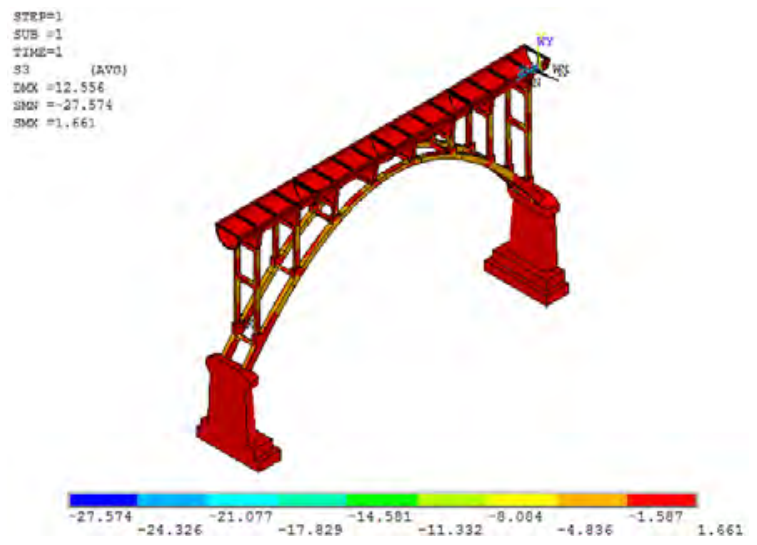

Figure 11. The third principal stress nephogram of aqueduct under case $5(\mathrm{MPa})$

$\mathrm{MPa}$, which appears in the junction of bent and arch under case 5

\section{B Deformation Analysis.}

Based on deformation analysis of reinforced concrete rib arch aqueduct structure, can get displacement change rule of aqueduct structure under different cases, total displacement nephogram of aqueduct structure under different cases shows in from Fig .12 to Fig . 15.

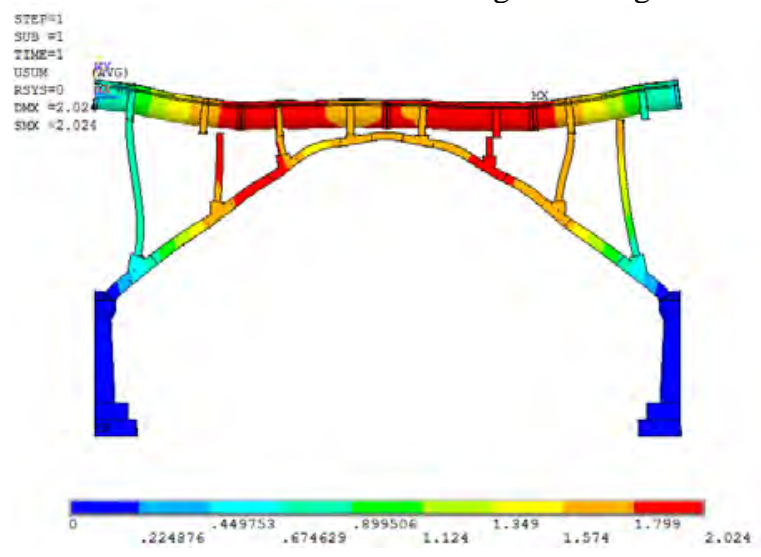

Figure 13. Total displacement nephogram of aqueduct under case 3 (mm) 


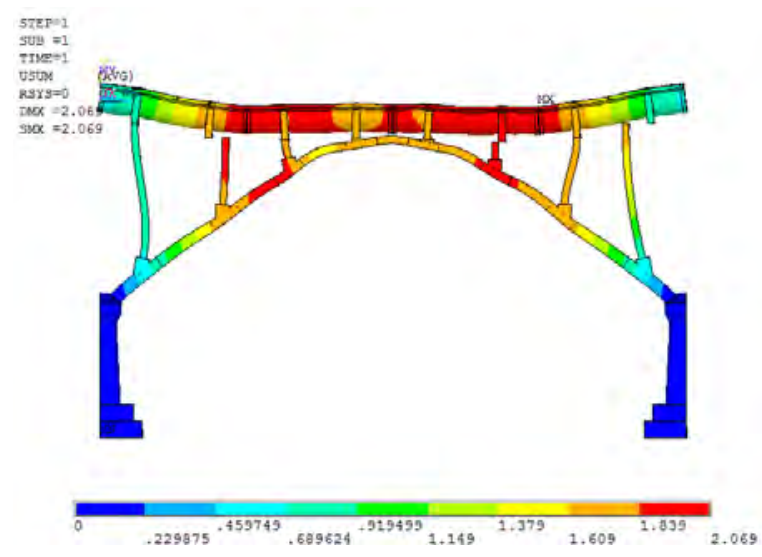

Figure 14. Total displacement nephogram of aqueduct under case 4 (mm)

As can be seen from Fig .12 to Fig .15, total displacement value of aqueduct under different cases is small, water pressure has large impact on total displacement value of aqueduct, seismic action mainly produces horizontal displacement, which lead total displacement values to increase sharply. Under case 1, the maximum total displacement of aqueduct is $1.40 \mathrm{~mm}$, under case 3 , the maximum total displacement of aqueduct is $2.02 \mathrm{~mm}$, under case 4 , the maximum total displacement of aqueduct is $2.07 \mathrm{~mm}$, under case 5, the maximum total displacement of aqueduct is $12.56 \mathrm{~mm}$.

\section{IV . CONCLUSION}

In conclusion, Feisha aqueduct adopts reinforced concrete rib arch scheme is reasonable. Aqueduct structure is stressing definite, simple, convenient for construction. Vertical displacement of aqueduct structure is small, can meet stiffness requirement.

\section{REFERENCE}

[1] Shanding Ma, Ruze Wang. Hydropower Station Structures (The Second Edition) $[\mathrm{M}]$. China Water Conservancy and Hydropower Press, 1996.

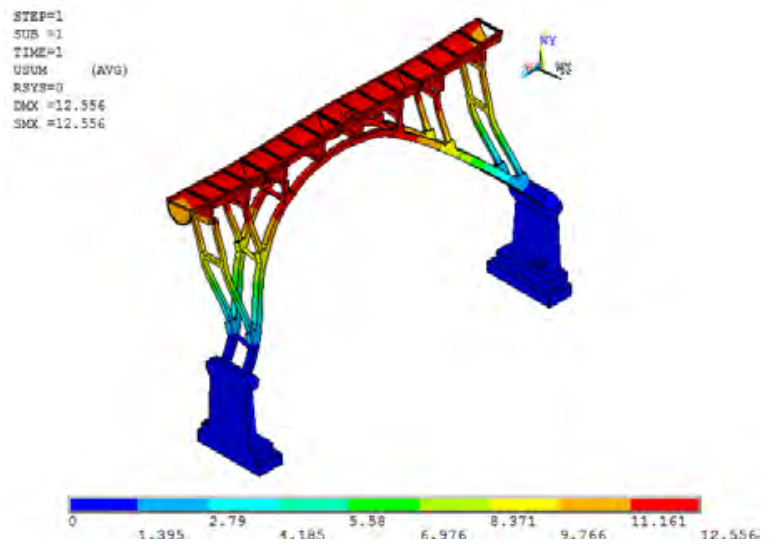

Figure 15. Total displacement nephogram of aqueduct under case 5 (mm)

[2] Xiaopei Sun,Xiaoling Wang,Ruirui Sun et al. Numerical Simulation for Water Conveyance of Inverted Siphon [C]. Advances in civil engineering II.2013:2407-2410.

[3] SL191-2008. Design Code for Hydraulic Concrete Structure[S] China Water Conservancy and Hydropower Press, 2008.

[4] Juan Li,Zhenwei Mu,Lin Li et al. Numerical Simulation and Model Test on Hydraulic Characteristics of Long-Distance Inverted Siphon [C]. Advances in Hydrology and Hydraulic Engineering.2012:1112-1116.

[5] Cheng Zibing,Wang Feng,Yan Wei et al. Experimental study on inverted siphon channel in South-to-North water diversion project $[\mathrm{C}]$. Advances in hydraulic physical modeling and field investigation technology.2011:685-689.

[6] Wenliang Ma,Weifang Zou. Three-dimensional finite element analysis of trench-buried inverted siphon structure [C]. 2012 7th International Conference on System of Systems Engineering. $2012: 380-382$

[7] Lun-Yan Wang,Lei Guo. Analysis on Concrete's Measures for Qin river Inverted-Siphons in winter [C]. Proceedings of the third international conference on modelling and simulation. vol. 2, Modelling and simulation in engineering.2010:70-73.

[8] Xucheng Wang. Finite Element Method [M]. Tsinghua University Press, 2003.

[9] Bofang Zhu. Finite Element Method Principle and Application [M]. China Water Conservancy and Hydropower Press, 1998.

[10] Huizhu Zhu, Deliang Chen, Fengnian Guan. Aqueduct [M] China Water Conservancy and Hydropower Press, 2005. 